\title{
Projeto Jovem Doutor: o aprendizado prático de estudantes de medicina por meio de atividade socioeducativa
}

\author{
Young Doctor Project-Health in Schools: potential learning of medical students \\ through taking part in socio-educational activity
}

\author{
Daniela Rodrigues da Silva1, Livia Rossetti de Abreu e Lima ${ }^{1}$, Ligia Mariani Cara ${ }^{1}$, Chao Lung Wen²
}

Silva DR, Abreu e Lima LR, Cara LM, Wen CL. Projeto Jovem Doutor: o aprendizado prático de estudantes de medicina por meio de atividade socioeducativa / Young Doctor Project-Health in Schools: potential learning of medical students through taking part in socio-educational activity. Rev Med (São Paulo). 2017 abr.-jun.;96(2):73-80.

RESUMO: O trabalho mostra a potencialização no aprendizado de estudantes de medicina (graduandos) através de participação em atividade sócio-educacional (Projeto Jovem Doutor-Saúde nas Escolas - PJD) usando recursos de educação interativa, vídeos, computação gráfica 3D e estruturas produzidas por impressora 3D (Homem Virtual). O PJD usou educação híbrida, reunindo plataforma educacional, ferramentas de mídias sociais, webconferências e objetos educacionais de aprendizagem com dinâmicas presenciais na estruturação de sistemática que proporcionou aprendizado flexível e em servico, agregando experiências e conhecimentos complementares aos graduandos participantes do projeto. Baseado em conteúdos que seguiam as prioridades do Ministério da Saúde do Brasil, os graduandos puderam conhecer aspectos da Atenção Primária, desenvolver várias atitudes e aprender conhecimentos não previstos na grade curricular médica normal. Por meio de responsabilidades atribuídas a cada um, os graduandos desenvolveram postura ativa para aprender os assuntos de forma contextualizada (pesquisa de temas, debate com professores e profissionais especialistas). Ao final do projeto, $81,9 \%$ (8 de 11) graduandos do PJD responderam que tiveram uma formação crítica, reflexiva e maior habilidade em comunicação. Todos $(100 \%)$, consideraram ter ampliado a capacidade de trabalho em equipe e conhecimentos em novas tecnologias. A interação dos graduandos com professores das escolas onde foram implantados o PJD levou-os a se tornarem "símbolos" para alunos do ensino fundamental II, promoveu a percepção dos futuros médicos sobre o seu papel no contexto social da saúde e estimulou a formação de vínculo social com alunos do ensino fundamental II. O aprendizado em serviç̧o, através de uma ação sócio-educacional, sob orientação de professores e profissionais especialistas, é uma boa forma de estimular $\mathrm{o}$ aprendizado dos alunos de medicina e está em conformidade com as diretrizes de 2014 do CNE/MEC para graduação em Medicina.

Descritores: Aprendizagem baseada em problemas; Comunicação em saúde; Telemedicina; Projetos; Educação médica; Cursos de capacitação; Aprendizagem; Estudantes de medicina.
ABSTRACT: This article presents the learning potentiation of medical students (undergraduates) through participation in socioeducational activity (Young Doctor Project-Health in Schools -YDP), using interactive educational resources, videos, 3D computer graphics and by 3D printer produced structures (Virtual Man). The YDP used hybrid education, bringing together educational platform, social media tools, web conferencing and educational learning objects with dynamic presence in the system structuring that provided flexible learning and in service, gathering experience and complementary expertise to the participants. Based on content that followed the priorities of the Ministry of Health of Brazil, the graduate students were able to learn aspects of primary care, develop various attitudes and acquire knowledge not covered by conventional medical curriculum. By being assigned to specific responsibilities, students developed active approach to learning the subjects in context (subjects research, discussion with teachers and professional experts). At the end of the project, $81.9 \%$ ( 8 of 11 ) of the YDP academics said that they had a critical training, reflective and greater communication skills. All $(100 \%)$, considered to have expanded the ability to work in teams and knowledge in new technologies. The interaction of the undergraduate with teachers from cities where the YDP were implemented led them to become "symbols" for middle school, promoted the perception of future doctors about their role in the social context of health and stimulated the formation of social bond with middle school. Learning in service, through a socio-educational action, under the guidance of teachers and professional experts is a good way to encourage the learning of medical students and complies with the guidelines of 2014 $\mathrm{CNE} / \mathrm{MEC}$ for undergraduates in medicine.

Keywords: Problem-basead learning; Health communication; Telemedicine; Projects; Medical education; Training courses; Students, medical.

Pôster apresentado no 54 COBEM - Congresso Brasileiro de Educação Medica, 12-15 out. 2016, Brasília, DF.

1. Graduanda em Medicina, Faculdade de Medicina da Universidade de São Paulo. Email: daniela.rodrigues@fm.usp.br, livia.rossetti. lima@usp.br, ligia.mariani@fm.usp.br.

2. Professor Associado da Disciplina de Telemedicina do Departamento de Patologia da Faculdade de Medicina da Universidade de São Paulo. Email: chao@usp.br.

Endereço para correspondência: Chao Lung Wen. Av. Dr. Arnaldo, 455 - sala 2103, $2^{\circ}$ andar. Cerqueira Cesar - São Paulo, SP, Brasil. CEP: 01246-903. 


\section{INTRODUÇÃO}

\section{Educação e Aprendizado}

Cucar, por definição, consiste no ato de
transmitir um saber e engloba, dois processos fundamentais: ensinar e aprender. Na profissão médica, cabe ao médico o papel de transmitir/propagar informações técnico-científicas de saúde à população. Entretanto, como em todo processo comunicacional, necessariamente bidirecional, é indispensável considerar a experiência pessoal do outro, seja em aspectos culturais, psicológicos ou socioambientais, a fim de garantir uma compreensão efetiva e recíproca das informações passadas. Desse modo, o sucesso prático no processo do cuidado em saúde, também depende da postura aberta do médico ao aprendizado, não apenas dos conhecimentos teóricos mas também daqueles depreendidos do contato humano e referentes ao arquétipo cultural da população.

\section{Promoção da Saúde}

A Carta de Ottawa, documento produzido na Primeira Conferência Internacional sobre Promoção da Saúde, ressalta a importância do envolvimento popular no que concerne a produção de práticas em saúde ao defender que "Promoção da saúde é o nome dado ao processo de capacitação da comunidade para atuar na melhoria de sua qualidade de vida e saúde, incluindo uma maior participação no controle deste processo". E vai além, ao considerar que a promoção da saúde não é de responsabilidade exclusiva do setor de saúde, requerendo, portanto, ações intersetoriais em direção de um bemestar global. Nesse sentido, emergem outros recursos fundamentais, dentre os quais destacamos a Educação. Reconhecendo a potencialidade dessa articulação, ainda no século XVII, foi criado na Alemanha, o Sistema Frank ${ }^{1}$, um código de saúde de caráter abrangente e que dava grande ênfase à educação, estabelecendo um estreito contato e marcando historicamente o início da associação entre as duas áreas.

\section{Programa de Saúde nas Escolas / Projeto Jovem Doutor}

No Brasil, surge em 2007, como estratégia do Ministério da Educação, o Programa de Saúde na Escola $(\mathrm{PSE})^{2}$ o qual prevê a melhoria da qualidade de vida da população brasileira por meio de uma Formação Integral dos estudantes da rede pública de ensino que realize ações de promoção, prevenção e atenção à saúde articuladas com o perfil epidemiológico local, considerando sempre o enfrentamento de vulnerabilidades que possam afetar o pleno desenvolvimento da comunidade escolar e proporcionando que cada cidadão usufrua precocemente dos direitos humanos que lhe são assegurados constitucionalmente.

Em fevereiro do mesmo ano, foi lançado o Projeto Jovem Doutor (PJD), coordenado pela Disciplina de Telemedicina do Departamento de Patologia da FMUSP (DTm), que integrou recursos tecnológicos (teleducação interativa e Homem Virtual) com recursos de comunicação fluida e vídeos contendo situações do cotidiano (vídeos de dramaturgia) para flexibilizar e potencializar a forma de transmissão de conhecimento. Com uso de vídeos, infográficos em forma de cartazes, e ambientes interativos de aprendizagem baseada em internet, o projeto procurou aproximar o público alvo com temas ligados à saúde, por meio de uma linguagem simples e acessível que facilitasse o entendimento dos assuntos, motivasse e promovesse maior difusão de conhecimentos importantes para promoção da saúde nas escolas, seguindo os eixos prioritários de Atenção Primária do Ministério da Saúde do Brasil.

Por meio de uma sistemática organizada e uso de plataforma educacional baseada em internet, o projeto foi adotado em várias instituições de ensino superior no Brasil, como atividade de extensão universitária envolvendo professores e estudantes da área de Saúde. Assim, o PJD, além da cidade de São Paulo, foi realizado em várias localidades como Tatuí (SP), Baurú (SP), Manaus (AM), Parintíns (AM), Macéio (AL), Vitória (ES), entre outros.

\section{Eixos de prioridades em Atenção Primária do Ministério da Saúde}

Em 2010, entre os eixos prioritários do Ministério da Saúde $(\mathrm{MS})^{3}$ em atenção primária foram lançadas as diretrizes para a organização das Redes de Atenção à Saúde (RAS), as quais preveem atenção especial aos temas da mortalidade materna e prevenção de doenças transmissíveis. A partir de então foi estruturada a Rede Cegonha, dirigida ao planejamento reprodutivo das famílias, além de cuidados voltado às mulheres grávidas e em período puerperal, com enfoque especial a adolescentes. Além disso, a Secretaria de Vigilância da Saúde (SVS) do MS também reforçou políticas públicas e educativas em algumas doenças dentre as quais se destacam as Doenças Sexualmente Transmissíveis (DSTs), dengue, Zika, Chikunguya e Gripe por vírus da Influenza H1N1.

\section{Pirâmide de Aprendizado}

Reconhecendo, todavia, que a eficiência da aprendizagem extrapola aos aspectos de conteúdo, guardando relação com a compreensão e vivência prática dos assuntos, podemos observar a teoria idealizada por Edgar Dale ${ }^{4}$, da Universidade do Estado de Ohio nos Estados Unidos, em 1946: "Audio-visual methods in Teaching” ou Pirâmide de Aprendizado. 


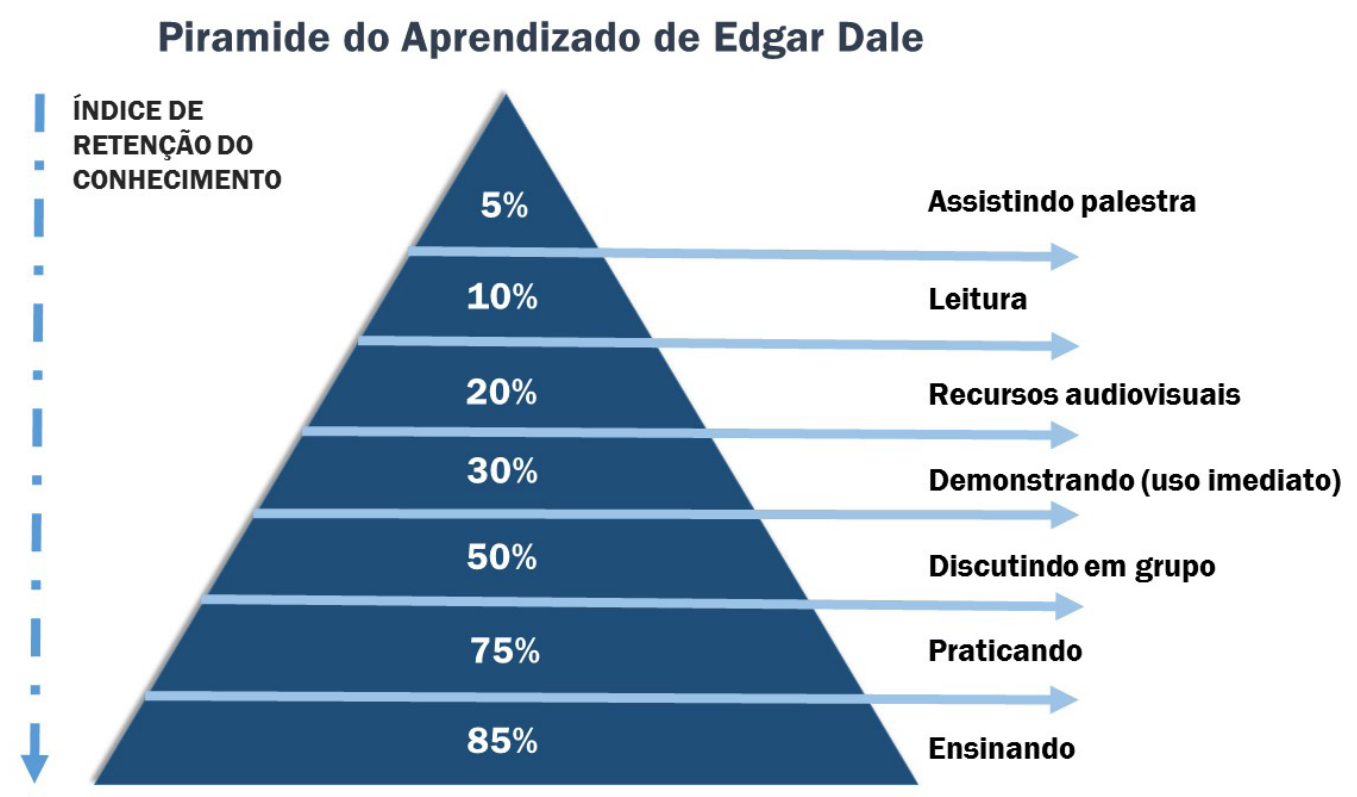

Figura 1. Pirâmide de aprendizagem

De acordo com o modelo apresentado, o processo de retenção de conhecimento aumenta na medida em que deixa de apenas assistir palestras ou ler para avançar na prática. A realização de atividades práticas confere um aprendizado mais eficiente, assim como a transmissão ativa de conhecimento para outra pessoa (ensino), que poderia aumentar para $85 \%$ o indicador de retenção de conhecimento, segundo o modelo. Este é um aspecto que deve ser considerado quando se pretende melhorar o aprendizado.

Complementando o pensamento de Confúcio segundo o qual "O que eu ouço, eu esqueço. O que eu vejo, eu lembro. O que eu faço, eu entendo”, a pirâmide de aprendizado de Edgar Dale prevê que quanto maior for a participação ativa e o envolvimento do estudante em seu processo educacional, maior será sua retenção de conhecimento.

\section{As novas Diretrizes Curriculares do MEC para Graduação de Medicina}

Reconhecendo a imprescindibilidade de uma reformulação do ensino médico nacional, estão sendo implementadas no Brasil até 2018, as Diretrizes Curriculares Nacionais do Curso de Graduação em Medicina ${ }^{5}$ (Ministério da Educação e Cultura, Resolução n ${ }^{\circ}$ 3, de 20 de junho de 2014) as quais determinam que durante a formação do graduando em Medicina, é necessária a articulação entre conhecimentos, habilidades e atitudes que contemplem as áreas de Atenção, Gestão e Educação em Saúde para o futuro exercício profissional do médico. Entre diversos pontos, seguem abaixo alguns aspectos importantes das Novas Diretrizes no contexto para este trabalho:
1) Comunicação, por meio de linguagem verbal e não verbal, com usuários, familiares, comunidades e membros das equipes profissionais, com empatia, sensibilidade e interesse, preservando a confidencialidade, a compreensão, a autonomia e a segurança da pessoa sob cuidado;

2) promoção da saúde, como estratégia de produção de saúde, articulada às demais políticas e tecnologias desenvolvidas no sistema de saúde brasileiro, contribuindo para construção de ações que possibilitem responder às necessidades sociais em saúde;

3) comunicação, incorporando, sempre que possível, as novas tecnologias da informação e comunicação (TICs), para interação a distância e acesso a bases remotas de dados;

4) liderança exercitada na horizontalidade das relações interpessoais que envolvam compromisso, comprometimento, responsabilidade, empatia, habilidade para tomar decisões, comunicar-se e desempenhar as ações de forma efetiva e eficaz, mediada pela interação, participação e diálogo, tendo em vista o bem-estar da comunidade;

5) trabalho em Equipe, de modo a desenvolver parcerias e constituição de redes, estimulando e ampliando a aproximação entre instituições, serviços e outros setores envolvidos na atenção integral e promoção da saúde;

6) aprender a aprender, como parte do processo de ensino-aprendizagem, identificando conhecimentos prévios, desenvolvendo a curiosidade e formulando questões para a busca de respostas cientificamente consolidadas, construindo sentidos para a identidade profissional e avaliando, criticamente, as informações obtidas, preservando a privacidade das fontes;

7) aprender com autonomia e com a percepção da 
Silva DR, et al. Projeto Jovem Doutor: o aprendizado prático de estudantes de medicina.

necessidade da educação continuada, a partir da mediação dos professores e profissionais do Sistema Único de Saúde, desde o primeiro ano do curso;

8) aprender interprofissionalmente, com base na reflexão sobre a própria prática e pela troca de saberes com profissionais da área da saúde e outras áreas do conhecimento, para a orientação da identificação e discussão dos problemas, estimulando o aprimoramento da colaboração e da qualidade da atenção à saúde;

9) comprometer-se com seu processo de formação, envolvendo-se em ensino, pesquisa e extensão e observando o dinamismo das mudanças sociais e científicas que afetam o cuidado e a formação dos profissionais de saúde, a partir dos processos de autoavaliação e de avaliação externa dos agentes e da instituição, promovendo o conhecimento sobre as escolas médicas e sobre seus egressos.

São consideradas competências a serem alcançadas a construção participativa do sistema de saúde e a participação social nos campos de ensino e aprendizagem das redes de atenção à saúde, cabendo ao aluno identificar as necessidades de aprendizagem tanto próprias (sendo capaz de aprender a aprender) como de grupos sociais e comunidades que respeitem sempre o conhecimento prévio e o contexto social de cada um, integrando informações e habilidades.

Diante desse contexto, o PJD mostra-se como uma possibilidade de inserir os estudantes de medicina em um cenário prático, focados em aprendizado em serviço, assumindo a responsabilidade com um conjunto de ações, incentivando a assumirem um papel ativo, de liderança e protagonismo em seu processo de aprendizagem. Orientados por professores, os estudantes podem desde o primeiro ano da graduação, realizar ações socioeducativas nas comunidades, responsabilizando-se pelas informações a serem transmitidas à população, em sincronia com as prioridades definidas pelo Ministério da Saúde.

\section{OBJETIVO GERAL}

Organizar e realizar uma ação socioeducativa (Projeto Jovem Doutor) em Métodos Contraceptivos e Prevenção DST, por meio de educação híbrida, com a participação dos estudantes de medicina, para promover o aprendizado em serviço, sob supervisão.

\section{OBJETIVOS ESPECÍFICOS}

- Organização e realização de curso baseada em educação híbrida ${ }^{6}$ (uso de plataforma educacional integrado com oficinas presenciais).

- Organização de equipe de estudantes de períodos diferentes da graduação de medicina para coordenação de subgrupos de alunos inscritos no PJD, durante a realização do curso à distância.
- Seleção e treinamento de ferramentas de comunicação síncrona e mídias sociais para agilização de discussão em equipe.

- Organização e estruturação de reuniões semanais de planejamento e sincronização.

\section{MÉTODO}

\section{Escolha do Material Interativo}

Foram selecionados os conteúdos da $2^{\text {a }}$ Série da Geração Saúde, produção resultante de trabalho cooperado da DTm com a TV-Escola/ MEC ${ }^{7}$. Trata-se de uma série formada por 15 episódios com propósito de transmitir informações para os estudantes das escolas públicas sobre Puberdade, Doenças Sexualmente Transmissíveis e prevenção, Vida do Soropositivo, Gravidez não planejada, Métodos Contraceptivos, entre outros temas. A produção caracterizou-se por concatenação de estória na parte dramatúrgica, sendo que cada episódio é composto por: estória de ficção do cotidiano (dramaturgia) + Homem Virtual (computação gráfica 3D do corpo humano) + Documentário Interativo (debate com profissional) e entrevista com especialistas.

Após a exibição da dramaturgia, constituída por capítulos de contextualização com estória do cotidiano para facilitar a associação entre o assunto com a problemática do cotidiano, o estudante poderia reforçar o aprendizado acessando o ambiente interativo de aprendizagem que contem textos para leituras complementares, sequências do Homem Virtual com narração e legendas (unidades conhecimento), e por fim, ter acesso ao Documentário Interativo e entrevista com especialistas sobre o tema, como recurso para fechamento do assunto.

\section{Familiarização com os materiais}

Os estudantes de medicina bolsistas, participantes do projeto Jovem Doutor, acessaram os materiais educacionais para fins de familiarização e aprendizado dos assuntos e da plataforma educacional baseada em internet que seria utilizado para realização da educação à distância.

\section{Planejamento da dinâmica de trabalho}

Foram estruturadas dinâmicas de reuniões semanais entre professor responsável e alunos bolsistas, para fins de debates dúvidas bem como sincronia de trabalho. Pelo uso de ferramenta interativa síncrona (software para webconferência), as reuniões eram em formato hibrido que poderia ser de participação presencial ou conectada a distância. As reuniões eram gravadas e inseridas no ambiente educacional do Portal do Jovem Doutor (http:// jovemdoutor.org.br), o que possibilitou o acesso posterior pelo grupo ou para fins de revisão do que foi discutido, ou para acesso pelos alunos que não puderam participar de 
Silva DR, et al. Projeto Jovem Doutor: o aprendizado prático de estudantes de medicina.

forma síncrona. Para a implantação do formato hibrido, foi feita previamente a capacitação dos bolsistas no uso do Adobe Connect.

Para otimização do trabalho, os bolsistas foram divididos em 4 grupos compostos por 5 alunos de diferentes períodos na graduação, para função de líderes de grupo. A bolsista mais graduada ( $5^{\circ}$ ano), em decorrência de experiência prática anterior, foi designada líder sênior, com função auxiliar o professor coordenador, e a esclarecer dúvidas dos 4 grupos em relação a execução das tarefas.

Para agilização da interação entre os alunos bolsistas, foram criados grupos fechados no Whatsapp e Facebook, por serem ferramentas de conhecimento de todos.

As atividades a serem realizados pelos estudantes envolviam:

- Acompanhamento do Curso de Difusão do Jovem Doutor realizado pela Pró-Reitoria de Cultura e Extensão Universitária da USP ( PRCE-USP), em formato de Teleducação Interativa e envolvia interação com os alunos inscritos, esclarecimento de dúvidas e envio de comunicação por email;

- Seleção semanal de 2 dúvidas mais frequentes postados no módulo de votador-de-dúvidas recorrente do ambiente educacional do Portal Jovem Doutor e a elaboração de respostas por meio de pesquisa prévia em literatura (saberes teóricos) e posteriores debates com profissionais especialistas, convidados pelo professor responsável, que contextualizavam as discussões sob os aspectos de experiências profissionais (saberes práticos). As respostas formuladas, eram postadas na plataforma digital em formato de vídeos ou texto;

- Estabelecer correlação dos conteúdos dos Livros Didáticos adotados pelas escolas dos alunos do ensino fundamental II participantes do Projeto Santos Jovem Doutor (PSJD), com os conteúdos interativos da $2^{\mathrm{a}}$ série da Geração Saúde;

- Interação com professores das escolas do PSJD e participação na realização de dois encontros presenciais ${ }^{8}$, e orientações para produção de vídeos e painéis sobre os temas abordados;

- Pesquisa sobre Doenças Sexualmente Transmissíveis (conteúdo integrante do PSJD) e Dengue, Zika e Chikunguya (temas complementares solicitados pelo município de Santos) por serem de grande importância social para a cidade;

- Participação na elaboração de dinâmicas, atividades presenciais em grupo e uso de outras ferramentas como as estruturas anatômicas produzidas por impressora 3D, para fins de explicação de temas específicos aos alunos do ensino fundamental II do PSJD.

\section{Participação em atividade presencial}

Alguns bolsistas em conjunto com professor responsável participaram de evento organizado pela Secretaria Municipal de Saúde de Santos, na cidade de Santos para promover encontro dos alunos e professores das escolas participantes do PSJD. No evento foram apresentados os vídeos produzidos pelos alunos de cada escola, segundo a realidade e o cotidiano dos adolescentes. Houve a interação entre os alunos com os estudantes bolsista de medicina que compartilharam as experiências pessoais sobre os desafios para aprovação na USP.

\section{Planejamento e recepção dos alunos do PSJD na Faculdade de Medicina da USP}

Como prêmio pela conclusão final do projeto, os alunos das escolas públicas de Santos, participantes do projeto, fizeram uma visita monitorada, em roteiro elaborado pelos estudantes bolsistas de medicina com o professor responsável. Conheceram vários pontos de destaque da FMUSP e Hospital das Clínicas, como laboratório do Homem Virtual e impressora 3D, CETEC (Centro de Tecnologia - familiarização com videoconferência), Museu Histórico da FMUSP e alguns prédios que compõem o complexo do Hospital das Clínicas.

\section{Aplicação de enquete de avaliação subjetiva dos bolsistas do Jovem Doutor}

Foi enviado aos bolsistas no final do projeto um questionário o qual procurou avaliar a percepção dos alunos quanto ao desenvolvimento de habilidades em comunicação, formação mais crítica e reflexiva e uso de novas tecnologias para o aprendizado.

\section{RESULTADOS}

Ao final de um ano o grupo ainda contava com 11 estudantes bolsistas, representados por graduandos do curso de medicina do $1^{\circ}$ ao $5^{\circ}$ ano. Os primeiros 2 meses do projeto foram dedicados à familiarização dos materiais do curso pelos bolsistas, de forma que estes se concentraram em assistir os vídeos da $2^{\mathrm{a}}$ series da Geração Saúde (dramaturgia + homem virtual + doc interativo + entrevista com especialistas) disponibilizados na plataforma do Jovem Doutor, leitura dos roteiros e textos complementares e discussão das dúvidas. Nessa primeira fase destinada a promover a homogeneização do grupo em relação aos temas, de discussão clara da dinâmica das atividades do projeto.

No mês subsequente iniciou-se o curso de difusão à distância do Projeto Jovem Doutor, pela PRCE-USP, seguindo sistemáticas previamente estabelecidas e gerenciamento de 4 subgrupos, liderados respectivamente por cada um dos grupos de bolsistas. Cada subgrupo com (cada grupo com 70 alunos), eram supervisionados pelos bolsistas e que interagiram com os participantes 
do curso por meio de email corporativo individual para esclarecimento de dúvidas. A bolsista mais graduada $\left(5^{\circ}\right.$ ano e com experiência de participação anterior no PJD) atuava como líder sênior, em apoio aos líderes de cada um dos 4 grupos.

Foram realizadas em torno de 35 reuniões presenciais, das quais cerca de $90 \%$ foram transmitidas pelo Adobe Connect para participantes que estavam em locais distantes, e gravadas e disponibilizadas na plataforma para acesso posterior pelos ausentes. O grupo de Facebook teve 37 postagens, resultante da interação de 9 bolsistas. Cada uma delas gerou uma quantidade significativa de comentários. As interações por Whatsapp somaram cerca de 850 mensagens no período de um ano. A maior parte dessa comunicação ocorreu em dias diferentes das datas das reuniões, sendo grande parte aos finais de semana. $\mathrm{O}$ grupo fechado dos professores da cidade de Santos compartilhou com os bolsistas mais de mil fotos das atividades realizadas nas escolas do PSJD.

Foi realizada uma visita à cidade de Santos, momento em que o grupo de bolsistas, sob a coordenação do professor responsável pelo projeto, teve o primeiro contato com os alunos do ensino fundamental II, conheceram algumas produções feitas pelos alunos, além compartilharam as suas experiências, falando sobre trajetória individual de vida no ensino médio em rumo ao ingresso na universidade. Neste momento, os bolsistas se tornaram como referência para os alunos de Santos. Duas semanas depois, os alunos de Santos foram recepcionados na Faculdade de Medicina da Universidade de São Paulo (FMUSP), quando receberam condecoração com "Pin Vermelho" (símbolo de reconhecimento de conclusão do PSJD), e foram guiados pelos estudantes de medicina do projeto, por um roteiro previamente planejado com o professor responsável.

As dúvidas mais votadas pela plataforma virtual foram divididas em grandes blocos e distribuídas entre os alunos de acordo com seus interesses pelos assuntos. Foram realizados debates com o professor responsável e profissionais especialistas convidados, como Nutricionistas, Ginecologistas, Dermatologista Sanitária (DST), Clínica Médica, Fisiatra e Dentista.

Os debates foram realizados no CETEC, que contava com um equipamento multicâmera para chaveamento automático em $360^{\circ}$ das câmeras de acordo da direção da voz, para gravação com posterior edição e disponibilização na plataforma. Familiarizados com a linguagem audiovisual, ao final do $2^{\circ}$ semestre de 2015 os alunos bolsistas conseguiram produzir por si só um vídeo institucional que apresentava os diferentes locais da FMUSP e o Hospital das Clínicas (HC) para uso pelos calouros 2016.

\section{Resultados de cinco eixos da enquete}

Gráfico 1. Obteve contato com novas tecnologias? (11 respostas)

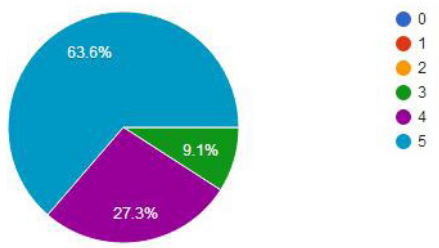

Gráfico 2. Proporcionou uma formação mais crítica? (11 respostas)

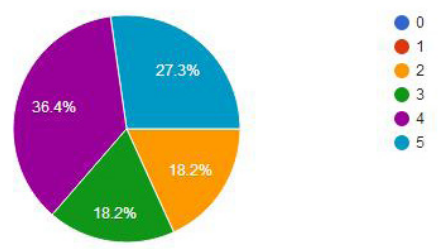

Gráfico 3. Proporcionou formação mais reflexiva? (11 respostas)
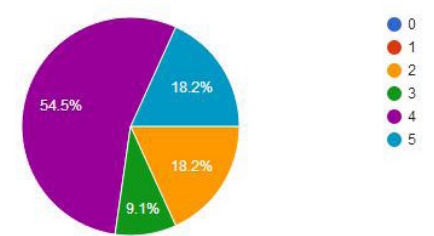

Gráfico 4. Que habilidade desenvolveu em comunicação? (11 respostas)

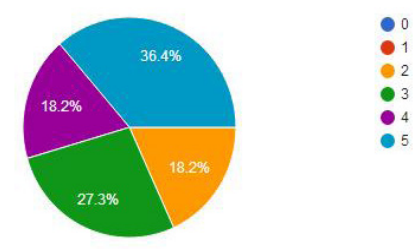

Gráfico 5. Proporcionou aprimoramento do trabalho em equipe? (11 respostas)

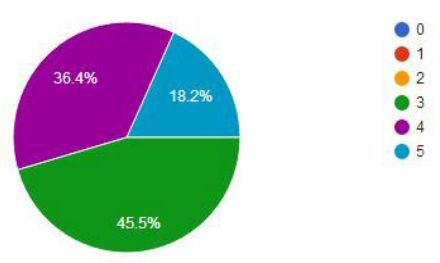

\section{DISCUSSÃO}

O Projeto Jovem Doutor é um modelo diferente de ensino-aprendizagem, menos formal, mais flexível 
e mais inserido no contexto das necessidades sociais, onde o conhecimento tem propósitos de transformação e a tecnologia, cada vez mais presente no dia a dia da população, é utilizada para formação de redes para propósitos de colaboração e de transmissão do saber ${ }^{9}$. É a aplicação de uma comunicação empática, com roteiros fluídos, integração entre informações cognitivas, infográficos, vídeos e atividades interativas (através da plataforma virtual ou presencial, com os professores locais) como forma de atrair o interesse dos jovens pelo tema de saúde, nas escolas. Estimula a busca ativa de conhecimentos e a criar novas formas de comunicação com os amigos.

Este projeto, no âmbito da formação de um estudante de medicina, tem o potencial de viabilizar a aprendizagem em serviço, por assumir a responsabilidade em promoção de saúde, sob orientação de professor. Em sincronia com a Pirâmide da Aprendizagem, o PJD estimula a aprendizagem dos estudantes de medicina por lhes atribuir pesquisar informações e ensinar a um público alvo. Este processo justamente alcança até um efeito de $85 \%$ na retenção de conhecimento.

A formação de grupos de estudantes bolsista, em diferentes períodos do curso médico, para liderarem subgrupo de alunos inscritos no curso de difusão do Jovem Doutor, foi baseado no Team Based Learning (TBL) e estimulou a questionarem permanentemente as informações usando a sistemática de familiarização dos conteúdos, levantamentos de dúvidas e debates com professor responsável e profissionais especialistas. Este método promoveu uma participação ativa por meio de atribuição de responsabilidades, iniciativa de análise crítica de materiais, e busca ativa de informações complementares. Nesse sentido, passa a valorizar o contato com profissionais mais experientes que podem proporcionar um enorme diferencial em relação aos livros: a troca de saberes e vivências.

A partir de aplicação de enquete elaborada pelos próprios alunos para realizar a avaliação subjetiva dos 11 bolsistas, foram identificados vários eixos. A avaliação de cada um dos quesitos foi feita baseando-se na escala de Likert (nota de 0 a 5). Os quesitos foram consideradas como positivas ("bom" ou "muito bom") apenas os resultados 3, 4 ou 5. $\mathrm{Na}$ análise final das respostas, algumas questões foram desprezadas, uma vez que se considerou que a forma do enunciado não foram suficientemente claras, podendo gerar dados incoerentes. Esses dados refletem a ideia de que tal postura ativa de aprendizagem envolvendo novos formatos para aquisição de conhecimento contribui ao desenvolvimento de um senso crítico no estudante. Cerca de $81,9 \%$ de um total de 11 bolsistas consideraram que o Projeto Jovem Doutor contribuiu para uma formação mais crítica e $81,2 \%$ no estímulo a formação reflexiva. Ainda, $81,9 \%$ deles consideraram bom ou muito bom a contribuição para o seu aprimoramento individual em habilidades de comunicação e 100\% avaliaram terem melhorado a sua capacidade de trabalhar em equipe.
Nesse sentido, os graduandos em medicina foram permanentemente desafiados ao serem colocados numa posição de disseminadores de conhecimento e com participação semanal de discussões em grupo, trabalhavam na construção e análise de atividades educacionais ${ }^{10}$, pautadas em responder as perguntas do votador-dedúvidas, e em desenvolver brincadeiras e dinâmicas para transmitir conhecimento das temáticas relacionadas, buscando ativamente novos saberes. Praticando, assim, o conhecimento aprendido em sala de aula e transformando-o em conhecimento prático vivencial, o que os leva a alcançar, segundo a pirâmide de aprendizado de Edgar Dale, alto grau de retenção de informação, ou seja, auto aprendizado acadêmico com o projeto.

Todos os estudantes (100\%) dos 11 bolsistas consideraram que a participação no projeto aumentou significativamente sua interação com novas tecnologias. $\mathrm{Na}$ prática, isso está relacionado ao uso de ferramentas para interação online, a partir do contato com o programa "Adobe Connect", por exemplo, foi possível realizar videoconferências de modo muito sofisticado durante várias atividades, como em nas reuniões semanais, propiciando maior flexibilização de horários nas gravações de vídeos explicativos sobre questões trazidas pelos próprios alunos do curso Jovem Doutor através do votador online de dúvidas das Plataformas Digitais de aprendizagem. Como futuros profissionais da saúde em tempos de ascensão do acesso a informações por meio de mídias digitais, é imprescindível que o aluno de medicina tenha contato com tecnologias como as supracitadas. Utilizar tais recursos na prática médica potencializa o dever do profissional médico em traduzir os conhecimentos científicos em linguagem popular por ampliar seu alcance e garantir qualidade da informação transmitida. Ademais, foi possível perceber o potencial dessa ferramenta para a gestão de grupos de trabalho, visto que a tecnologia viabiliza a interação de grupos distantes (geograficamente) entre si em tempo real, bastando que se tenha acesso à internet e um smartphone ou tablet.

A utilização de computação gráfica e impressoras 3D através do Projeto Homem Virtual assumiu papel de destaque no curso, uma vez que se torna possível condensar um grande número de informações complexas e transmiti-la de forma clara e rápida, viabilizando o processo educacional em ambiente presencial ou em educação a distância. No que diz respeito aos alunos de ensino fundamental II e médio, pode-se dizer que a técnica também possui a vantagem de um ensino bastante fidedigno de anatomia sem a utilização de peças reais, através das estruturas impressas em tamanho real e com grande precisão, em plástico colorido.

Dessa forma, é criado um ambiente global de otimização do aprendizado através da troca de saberes entre a academia e a comunidade ${ }^{11}$. $\mathrm{O}$ uso de aplicativos de mensagem (whatsapp) e redes sociais (facebook) para gerenciamento do grupo e troca de informações sobre o 
Silva DR, et al. Projeto Jovem Doutor: o aprendizado prático de estudantes de medicina.

projeto, revelam o poder criativo dos estudantes em utilizar recursos comuns para finalidade de organização e educação, estando permanentemente em contato com as atribuições do projeto. Quanto ao uso de correio eletrônico, a fim de preservar a privacidade dos bolsistas foi a criado de um e-mail temporário corporativo.

Um outro destaque foi a riqueza dos encontros entre os estudantes de medicina e os alunos de ensino fundamental, tanto no evento sobre o Projeto Jovem Doutor organizado pela Secretaria Municipal de Saúde de Santos, quanto na visita monitorada à FMUSP. Os bolsistas tiveram uma oportunidade excepcional de se aproximar da comunidade e um importante espaço para o compartilhamento de experiências. Alguns bolsistas, por exemplo, contaram como foi sua trajetória partindo de escolas públicas até alcançarem a Universidade de São Paulo, tornando-se uma espécie de referencia simbólica para esses alunos e contribuindo ao estabelecimento um vínculo de amizade, respeito e admiração. Além disso, puderam vivenciar, na prática, a importância do conceito de 'competência cultural' visto que pela primeira vez, como representantes oficiais da FMUSP, tiveram a responsabilidade de adaptar

\section{REFERÊNCIAS}

1 Figueiredo TAM, Machado VLT, Abreu MMS. A saúde na escola: um breve resgate histórico. Ciênc Saúde Coletiva. 2010;15(2):397-402. http://dx.doi.org/10.1590/S141381232010000200015 .

2 Brasil. Ministério da Educação. Programa Saúde nas Escolas [ictado 20 jul. 2016]. Disponível em: http://portal.mec.gov.br/ pet/194-secretarias-112877938/secad-educacao-continuada223369541/14578-programa-saude-nas-escolas.

3 As Redes de Atenção à Saúde [citado 15 jul. 2016]. Disponível em: http://dab.saude.gov.br/portaldab/smp_ras.php

4 Sprawls P. Evolving models for medical physics education and training: a global perspective. Biomed Imaging Interv J. 2008;4(1):e16. doi: 10.2349/biij.4.1.e16.

5 Novas Diretrizes Curriculares para o Curso de Medicina [citado 10 jun. 2016]. Disponível em: http://portal.mec.gov. br/cne/arquivos/pdf/Med.pdf.

6 Spinardi ACP, Blasca WQ, Wen CL, Maximino LP. Telefonoaudiologia: ciência e tecnologia em saúde. PróFono Rev Atual Cient. 2009;21(3):249-54. http://dx.doi. org/10.1590/S0104-56872009000300012.

7 TV Escola MEC [citado 28 jun. 2016]. Disponível em: http:// tvescola.mec.gov.br/tve/home. um 'conteúdo médico' a uma linguagem mais acessível a fim de transmiti-lo à comunidade. Nesse contexto, foi possível perceber que a atual formação médica brasileira ainda é muito falha no preparo dos alunos para habilidades comunicacionais práticas. Focada quase exclusivamente em aspectos biológicos, grande parte das escolas médicas fornece poucos espaços para que os graduandos se abram ao convívio real com as comunidades e exerçam papel de protagonistas junto a projetos sociais, assumindo responsabilidades frente à população e ao planejamento do cuidado, partindo das necessidades empíricas em saúde daquela região.

\section{CONCLUSÃO}

O projeto jovem doutor promoveu a aprendizagem complementar dos alunos da graduação de medicina, fortalecendo a formação crítica, reflexiva, comunicação, trabalho em equipe e tecnológica, que não fazem parte da grade curricular convencional e está de acordo com a novas diretrizes curriculares do CNE/MEC.

8 Toassa EC, Leal GVS, Wen CL, Philippi ST. Atividades lúdicas na orientação nutricional de adolescentes do Projeto Jovem Doutor. Nutrire. 2010;35(3):17-27. Disponível em: http://files.bvs.br/upload/S/1519-8928/2010/v35n3/a1754. pdf.

9 Wen CL, Silveira PSP, Azevedo RS, Bohm GM. Internet discussion lists as an educational tool. J Telemed Telecare. 2000;6(5):302-4. doi: 10.1258/1357633001935842.

10 Campos FE, Haddad AE, Wen CL, Alkmin MBM, Cury PM. O programa nacional de telessaúde no Brasil: um instrumento de apoio à atenção primária. Latin Am J Telehealth. 2009;1(1):39-66. Disponível em: http://cetes.medicina.ufmg. br/revista/index.php/rlat/article/view/11/3.

11 Wen CL. Telemedicina e telessaúde - um panorama no Brasil. Informática Pública. 2008;10(2):7-15. Disponível em: http://www.ip.pbh.gov.br/ANO10_N2_PDF/telemedicina telesaude.pdf

12 Gundim RS, Wen CL. A Brazilian study of the sustainability of telemedicine centres. J Telemed Telecare. 2009;15(3):159. Available from: http://journals.sagepub.com/doi/pdf/10.1258/ jtt.2009.003017. 